\title{
Phylogenetic evidence for the transfer of Eubacterium lentum to the genus Eggerthella as Eggerthella lenta gen. nov., comb. nov.
}

\author{
Akiko Kageyama, Yoshimi Benno and Takashi Nakase
}

Japan Collection of Microorganisms, The Institute of Physical and Chemical Research (RIKEN), Wako, Saitama 3510198, Japan
Author for correspondence: Akiko Kageyama. Tel: +81484671111 ext. 5141. Fax: +81484624619. e-mail: kageyama@ulmus.riken.go.jp

\begin{abstract}
Eubacterium lentum has unique phenotypic characters within the genus Eubacterium. The 165 rRNA sequence of Eubacterium lentum was determined and its phylogenetic position was defined. This micro-organism is a member of the genus Eubacterium but it is not closely related to Eubacterium limosum, the type species of the genus Eubacterium, and is nearer to Collinsella aerofaciens and Coriobacterium glomerans. A PCR-based identification system using species-specific primers designed on the basis of DNA sequences encoding the 16S rRNA of strains of Eubacterium lentum, Collinsella aerofaciens and Coriobacterium glomerans is described. A species-specific primer set can distinguish Eubacterium lentum from Eubacterium limosum or closely related species including Collinsella aerofaciens, Coriobacterium glomerans and Atopobium species. This species-specific PCR method can be used to identify Eubacterium lentum-like species isolated from human faeces. On the basis of the 165 rRNA sequence divergence from Collinsella aerofaciens and Coriobacterium glomerans and the presence of unique phenotypic characters, a new genus, Eggerthella gen. nov., is proposed for Eubacterium lentum, with one species, Eggerthella lenta comb. nov. The type strain of Eggerthella lenta is JCM 9979'.
\end{abstract}

Keywords: Eggerthella lenta; $16 \mathrm{~S}$ rDNA; PCR using genus-specific primers

\section{INTRODUCTION}

Eubacterium lentum Prévot's strain 1899B was isolated from a rectal tumour in 1938 (Prévot, 1938). Eggerth provided the original description of Eubacterium lentum on the basis of 23 strains from human faeces; the organism was originally named 'Bacteroides lentus', but no type strain was designated (Eggerth, 1935). Moore et al. (1971) emended the description of Eubacterium lentum on the basis of a study of 53 strains, including another 38 strains isolated from human infections and three strains labelled Eubacterium lentum from the Prévot collection. Eubacterium lentum is a Gram-positive, obligately anaerobic, non-spore-forming rod. Propionibacterium, Lactobacillus, Actinomyces and Bifidobacterium have the same phenotype but these were differentiated by acid production from glucose. Propionibacterium

The DDBJ accession number for the 165 rRNA sequence of strain JCM $9979^{\top}$ is $A B 011817$. species produce propionic acid as a major product, Lactobacillus species produce lactic acid as the sole major acid product, Actinomyces species produce large amounts of succinic acid (in the presence of $\mathrm{CO}_{2}$ ) and lactic acid, sometimes with acetic and formic acids, and Bifidobacterium species produce acetic and lactic acids (acetic $>$ lactic), with or without formic acid, as the major acid products. Species that are Grampositive, obligately anaerobic, non-spore-forming rods and do not belong to any of the above genera are classified as Eubacterium. Eubacterium lentum produces little or no gas or product from 0 to $1.5 \mathrm{meq}$ of acetic, formic, succinic or lactic acids, or from all four acids, so it is defined as a member of Eubacterium. Cells of Eubacterium lentum are small, non-motile rods that do not produce acid from glucose and do not produce indole or liquefy gelatin; these characters differentiate the taxon from other species of the genus Eubacterium.

The intestinal microflora in humans and animals consists of several micro-organisms, including 
anaerobes and aerobes. The genus Eubacterium of anaerobic, Gram-positive, non-spore-forming rods is one of the predominant micro-organisms in the intestinal microflora. Collinsella aerofaciens, which has been transferred from Eubacterium because of its phylogenetic and phenotypic characters (Kageyama et al., 1999), Eubacterium rectale, Eubacterium lentum and Eubacterium cylindroides are dominant in the human intestine (Benno et al., 1986; Finegold \& Sutter, 1978; Moore \& Holdeman, 1974). Eubacterium lentum has anti-tumour mechanisms and the bacterial components responsible for the anti-tumour effect have been investigated (Hatta, 1995; Morinaga et al., 1988). Eubacterium lentum inactivates the cardiac glycoside digitoxin by reducing the double bond in the lactone ring (Chandrasekaran et al., 1987).

The genus Eubacterium has a broad definition, so this genus has for a long time acted as a depository for a large number of phenotypically diverse species. It is not only phenotypically heterogeneous, but also phylogenetically heterogeneous, with species dispersed among many genera, and includes organisms that are not related phylogenetically.

In this study, in order to understand the taxonomic position of Eubacterium lentum JCM $9979^{\mathrm{T}}$, we determined the sequence of the 16S rRNA gene and analysed its phylogenetic position. On the basis of this $16 \mathrm{~S}$ rRNA sequence data and the phenotypic characters, we propose that this organism should be classified as Eggerthella lenta gen. nov., comb. nov. A simple PCR identification method using Eggerthella lenta species-specific primers was established and its simplicity and utility were confirmed.

\section{METHODS}

Bacterial strains studied and cultivation. The bacterial strains used in this study were 17 strains that have Eubacterium lentum-like characters isolated from human faeces (Table 1) and the following type strains: Eubacterium lentum JCM $9979^{\mathrm{T}}$, Collinsella aerofaciens JCM $10188^{\mathrm{T}}$, Coriobacterium glomerans JCM 10262 ${ }^{\mathrm{T}}$, Eubacterium limosum JCM $6421^{\mathrm{T}}$, Eubacterium barkeri JCM $1389^{\mathrm{T}}$, Atopobium minutum JCM $1118^{\mathrm{T}}$, Eubacterium fossor JCM $9981^{\mathrm{T}}$, Eubacterium combesii JCM $9988^{\mathrm{T}}$, Eubacterium multiforme JCM $6484^{\mathrm{T}}$, Eubacterium nitritogenes JCM $6485^{\mathrm{T}}$, Eubacterium tenue $\mathrm{JCM} 6486^{\mathrm{T}}$, Eubacterium moniliforme JCM 9990 ${ }^{\mathrm{T}}$, Eubacterium cylindroides JCM 10261 ${ }^{\mathrm{T}}$, Lactobacillus plantarum JCM $1149^{\mathrm{T}}$, Bifidobacterium bifidum JCM $1255^{\mathrm{T}}$ and Propionibacterium propionicum $\mathrm{JCM} 5830^{\mathrm{T}}$. All bacterial strains were cultivated in an anaerobic chamber for $2 \mathrm{~d}$ at $37^{\circ} \mathrm{C}$ on EG agar (premixed EG agar; Eiken Chemical Co.), which contains $3 \mathrm{~g}$ beef extract, $5 \mathrm{~g}$ yeast extract, $10 \mathrm{~g}$ peptone, $1.5 \mathrm{~g}$ glucose, $0.5 \mathrm{~g}$ L-cysteine $\mathrm{HCl}, 0.2 \mathrm{~g}$ L-cystine, $4 \mathrm{~g} \mathrm{Na}_{2} \mathrm{HPO}_{4}, 0.5 \mathrm{~g}$ soluble starch, $0.5 \mathrm{~g}$ Tween $80,0.5 \mathrm{~g}$ silicone and $15 \mathrm{~g}$ agar $\mathrm{l}^{-1}, \mathrm{pH} 7 \cdot 7$, supplemented with $5 \%$ horse blood.

16S rDNA sequencing. The $16 \mathrm{~S}$ rRNA gene was amplified by PCR with prokaryotic $16 \mathrm{~S}$ rDNA universal primers $27 \mathrm{~F}\left(5^{\prime}-\right.$ AGAGTTTGATCCTGGCTCAG-3') and 1492R (5'-GGTTACCTTGTTACGACTT-3'). PCR was performed with
Table 1. List of Eubacterium lentum-like strains isolated from human faeces and their sources

\begin{tabular}{|lll|}
\hline Strain & \multicolumn{1}{c|}{ Source } & Year \\
\hline A2-3 & Patient with ulcerative colitis & 1978 \\
A2-184 & Canadian & 1982 \\
A3-99 & Healthy adult & 1981 \\
A3-104 & Healthy adult & 1981 \\
A3-112 & Healthy adult & 1981 \\
A3-125 & Healthy adult & 1981 \\
A3-252 & Healthy adult & 1981 \\
A5-166 & Infant & 1984 \\
A5-189 & Patient with ulcerative colitis & 1982 \\
A5-190 & Patient with Crohn's disease & 1982 \\
A9-162 & Patient with colon cancer & 1979 \\
RCA1-1 & Healthy adult & 1981 \\
RCA1-16 & Healthy adult & 1981 \\
RCA1-18 & Healthy adult & 1981 \\
RCA2-10 & Healthy adult & 1981 \\
RCA2-37 & Healthy adult & 1981 \\
RCA58-92 & Healthy adult & 1981 \\
\hline
\end{tabular}

a DNA thermal cycler (Perkin-Elmer Cetus) using 30 cycles consisting of denaturation at $94^{\circ} \mathrm{C}$ for $60 \mathrm{~s}$, primer annealing at $55^{\circ} \mathrm{C}$ for $150 \mathrm{~s}$ and primer extension at $72{ }^{\circ} \mathrm{C}$ for $150 \mathrm{~s}$ (with $30 \mathrm{~s}$ added per cycle). Ligation was performed using plasmid pT7 Blue T vector (Novagen) and a ligation kit (Takara Shuzo) as recommended by the manufacturer. Transformation was done using Escherichia coli MJ1190 competent cells and colonies were selected for analysis. Plasmids were prepared for sequencing by the alkaline lysis method. Sequencing was performed using the ALFred AutoCycle Sequencing Kit (Pharmacia Biotech) with an ALFexpress DNA sequencer (Pharmacia Biotech). Nucleotide substitution rates ( $K_{\text {nuc }}$ values) were calculated (Kimura $\&$ Ohta, 1972) and phylogenetic trees were constructed by the neighbour-joining method (Saitou \& Nei, 1987). The topology of the trees was evaluated by performing a bootstrap analysis of the sequence data with CLUSTAL $w$ software (Thompson et al., 1994) (Fig. 1). The DNAML program in the PHYLIP 3.5c package (Felsenstein, 1985) was used for the maximum-likelihood analysis, with the default transition/transversion ratio of 2.0 (Fig. 2).

Primer design. In order to understand the taxonomic position of Eubacterium lentum, we determined the $16 \mathrm{~S}$ rRNA sequences of Eubacterium lentum JCM $9979^{\mathrm{T}}$ and compared these sequences with other Eubacterium species and some other genera (obtained from the Ribosome Database Project). As a result of this comparison, we found that Eubacterium lentum was far from other Eubacterium species but near to Collinsella aerofaciens and Coriobacterium glomerans. Therefore, to design the speciesspecific primers, we compared the 16S rRNA sequences of Eubacterium lentum, three Collinsella aerofaciens strains and Coriobacterium glomerans and searched for positions that differed between Eubacterium lentum, Collinsella aerofaciens and Coriobacterium glomerans. We designed the speciesspecific primers so that the $\mathrm{G}+\mathrm{C}$ content was about $50 \mathrm{~mol} \%$ and the number of bases was about 20 . We designed two sets of primers: LEN-F1 and LEN-R1 and LEN-F2 and LEN-R2. The closest known relatives of these 


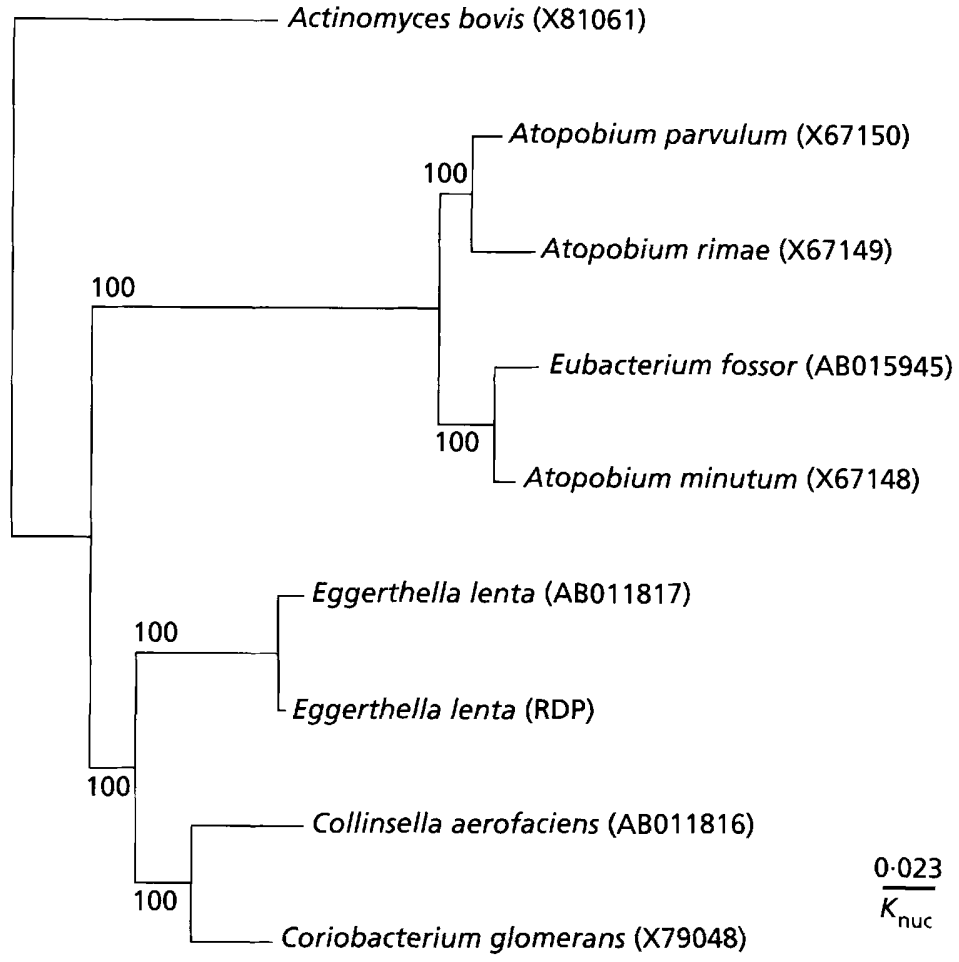

Fig. 1. Unrooted phylogenetic tree of Eggerthella lenta (= Eubacterium lentum) and close relatives derived from 165 rDNA sequences. The tree was created using the neighbour-joining method and $K_{\text {nuc }}$ values. The numbers on the tree indicate bootstrap values for the branch-points. The sequence data for species other than Eggerthella lenta (AB011817) were obtained from the database.

primers were determined by performing a sequence database search by using FASTA.

PCR. PCR was performed with a DNA thermal cycler using 25 cycles consisting of denaturation at $94^{\circ} \mathrm{C}$ for $60 \mathrm{~s}$, primer annealing at $63{ }^{\circ} \mathrm{C}$ for $150 \mathrm{~s}$ and primer extension at $72{ }^{\circ} \mathrm{C}$ for $150 \mathrm{~s}$ using one of the sets of primers mentioned above. The sample DNA was prepared by suspending the cultured colony in distilled water, heating at $100{ }^{\circ} \mathrm{C}$ for $5 \mathrm{~min}$ and then cooling. Each amplification was performed using Eubacterium lentum as a positive control and Collinsella aerofaciens as a negative control. After PCR, an $8 \mu \mathrm{l}$ aliquot of amplified sample from each PCR tube was electrophoresed through a $2 \%$ agarose gel (Sigma) in TAE buffer for $30 \mathrm{~min}$ at $100 \mathrm{~V}$. Amplification products were visualized and photographed under a UV light transilluminator after 30 min of ethidium-bromide staining. The molecular masses of the amplicons were determined by comparison with commercial DNA molecular mass markers.

Primer species specificity.Primer specificity was defined as the ability of a primer to anneal specifically only to Eubacterium lentum $16 \mathrm{~S}$ rRNA. The specificity of the primers was tested against the following organisms: Eubacterium lentum JCM 9979 , Eubacterium limosum $\mathrm{JCM} 6421^{\mathrm{T}}$, Eubacterium barkeri $\mathrm{JCM} 1389^{\mathrm{T}}$, Eubacterium fossor JCM $9981^{\mathrm{T}}$, Eubacterium combesii JCM $9988^{\mathrm{T}}$, Eubacterium multiforme JCM $6484^{\mathrm{T}}$, Eubacterium nitritogenes JCM $6485^{\mathrm{T}}$, Eubacterium tenue JCM $6486^{\mathrm{T}}$, Eubacterium moniliforme JCM $9990^{\mathrm{T}}$, Eubacterium cylindroides JCM $10261^{\mathrm{T}}$ and members of six other genera (Collinsella aerofaciens JCM $10188^{\mathrm{T}}$, Coriobacterium glomerans JCM $10262^{\mathrm{T}}$, Atopobium minutum JCM $1118^{\mathrm{T}}$, Lactobacillus plantarum JCM $1149^{\mathrm{T}}$, Bifidobacterium bifidum JCM $1255^{\mathrm{T}}$ and Propionibacterium propionicum JCM $5830^{\mathrm{T}}$ ).

Amplification of isolated strains. First, strains were isolated from human faeces by culturing on EG agar plates under anaerobic conditions and many colonies were obtained. We then examined cell morphology and sugar fermentation to check whether these strains were Eubacterium lentum. Finally, 17 Eubacterium lentum-like strains isolated from human faeces were tested by this PCR method.

\section{RESULTS}

\section{$16 S$ rDNA sequence analysis}

More than 1400 bases of the 16S rDNA sequence (positions 28-1492; Escherichia coli numbering system) of Eubacterium lentum JCM $9979^{\mathrm{T}}$ were determined and this sequence has been deposited in the DDBJ database. A database search demonstrated that Eubacterium lentum belongs to the family Coriobacteriaceae, which contains the genera Coriobacterium and Atopobium. A phylogenetic analysis was performed including all species of the family Coriobacteriaceae to elucidate the topology of Eubacterium lentum and the species of the family Coriobacteriaceae in two different analysis (a neighbour-joining method and maximum-likelihood analysis) (Figs 1 and 2). Both phylogenetic analyses showed that Eubacterium lentum JCM $9979^{\mathrm{T}}$ is member of the Coriobacteriaceae and is closely related to the species Collinsella aerofaciens and Coriobacterium glomerans (Haas \& König, 1988).

\section{Primer design and specificity}

The results of $16 \mathrm{~S}$ rRNA sequence analysis revealed that Eubacterium lentum has high sequence identity to Collinsella aerofaciens and Coriobacterium glomerans. 


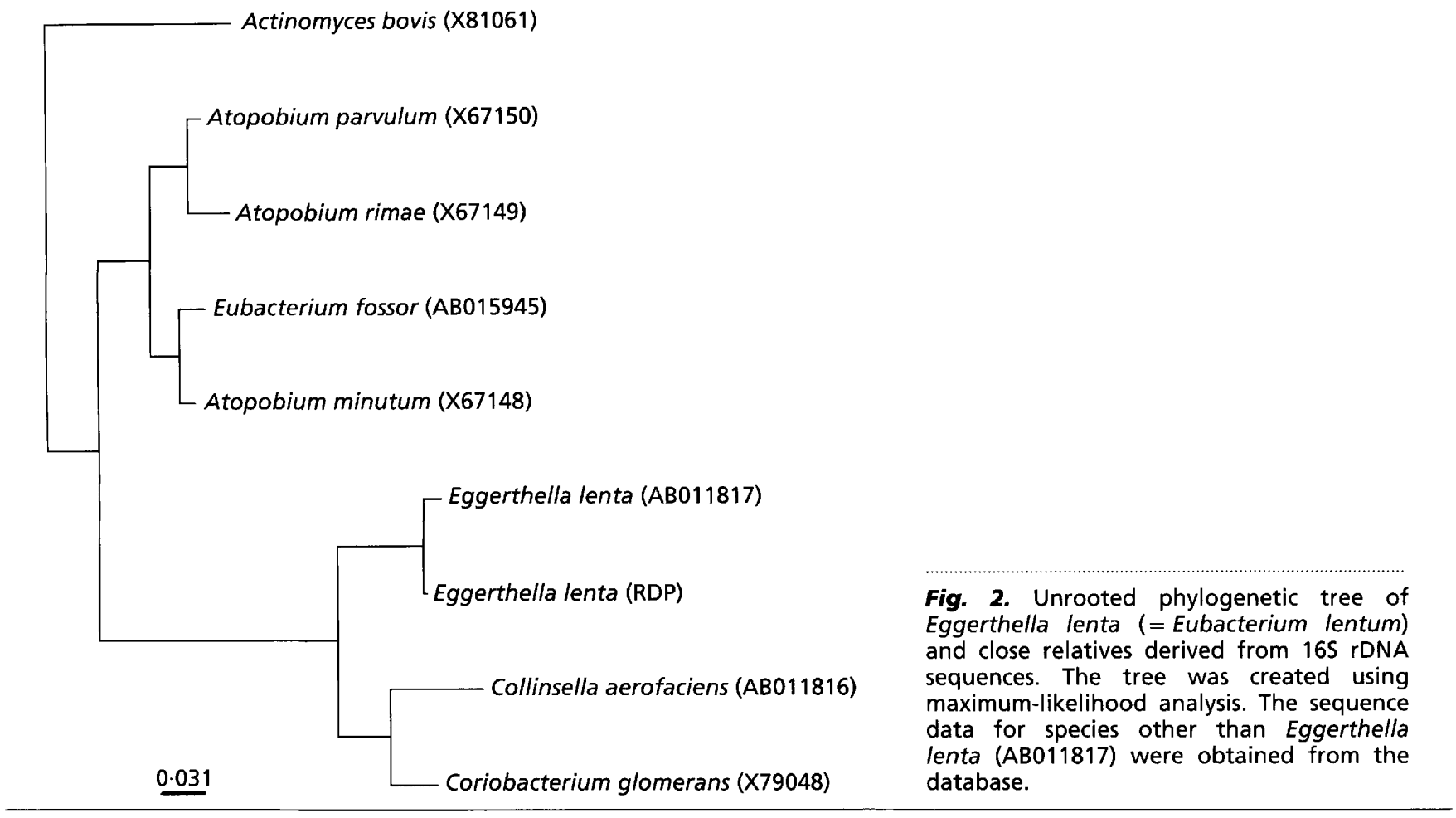

Table 2. Percentage identity of $16 \mathrm{~S}$ rRNA of Eubacterium lentum to other related taxa

\begin{tabular}{|lcccccc|}
\hline Taxon & Bases & $\mathbf{1}$ & $\mathbf{2}$ & $\mathbf{3}$ & $\mathbf{4}$ & $\mathbf{5}$ \\
\hline 1. Eubacterium lentum & 1472 & - & & & & \\
2. Collinsella aerofaciens & 1463 & 85.4 & - & & & \\
3. Coriobacterium glomerans & 1435 & 87.8 & $90 \cdot 7$ & - & & \\
4. Atopobium minutum & 1492 & 85.7 & 85.0 & 85.8 & - & \\
5. Atopobium rimae & 1376 & 84.5 & 83.5 & $84 \cdot 3$ & $91 \cdot 8$ & - \\
6. Atopobium parvulum & 1396 & 85.1 & 84.7 & 84.9 & $93 \cdot 4$ & $96 \cdot 1$ \\
\hline
\end{tabular}

Overall 16S rRNA sequence identities are given for Eubacterium lentum, Collinsella aerofaciens, Coriobacterium glomerans and Atopobium species in Table 2. We next compared the $16 \mathrm{~S}$ rRNA sequences of Eubacterium lentum, three Collinsella aerofaciens strains and Coriobacterium glomerans and found mismatched positions. Finally, we designed and synthesized two sets of primers: LEN-F1 (5'-CATGAAGTGGCGAACGGGTGA-3'; positions 94-116, Escherichia coli numbering system), LEN-F2 (5'CTTGCTCCGGACAACCTTGGGA-3'; positions 139-160), LEN-RI (5'-CTTCTGCTGCAGGTACCGTCGAATT-3'; positions 497-452) and LEN-R2 (5'TCTACCGAACTCGAGCCTCCCA-3'; positions 665-644). All primers consisted of about 20 bases and their $\mathrm{G}+\mathrm{C}$ content was about $50 \mathrm{~mol} \%$. We attempted PCR using four combinations of primers: LEN-F1 + LEN-R1, LEN-F1 + LEN-R2, LENF2+ LEN-R1 and LEN-F2+LEN-R2. The equences. The tree was created using database.

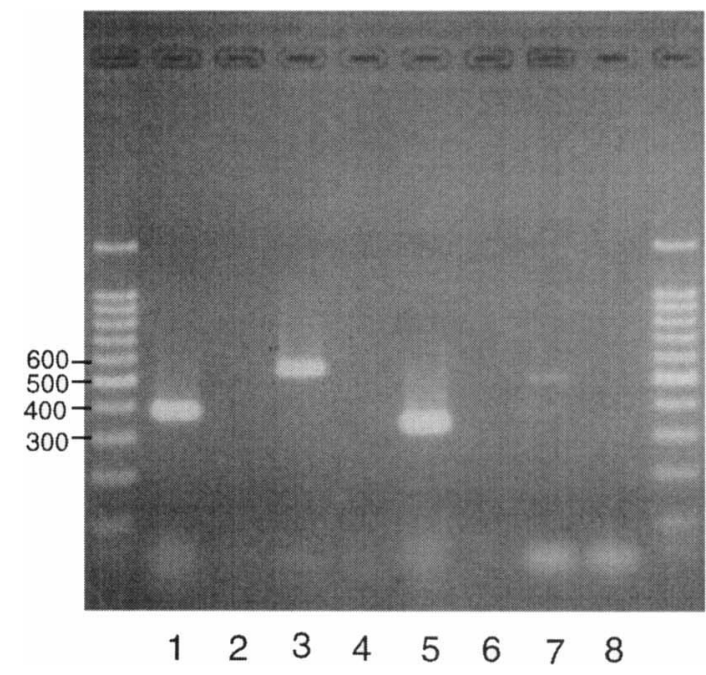

Fig. 3. Amplification of the 165 rRNA gene by PCR with primers LEN-F1, LEN-F2, LEN-R1 and LEN-R2. Lanes on both ends contain molecular mass markers. DNA from Eggerthella lenta (oddnumbered lanes) and Collinsella aerofaciens (even-numbered lanes) was amplified with primers LEN-F1 and LEN-R1 (lanes 1 and 2), LEN-F1 and LEN-R2 (lanes 3 and 4), LEN-F2 and LEN-R1 (lanes 5 and 6), and LEN-F2 and LEN-R2 (lanes 7 and 8). A product was always amplified from DNA of Eggerthella lenta JCM $9979^{\top}$ and no product was amplified from DNA of Collinsella aerofaciens JCM $10188^{\mathrm{T}}$ with any primer combination.

amplicons expected contained $383 \mathrm{bp}$ (positions 94-497) (LEN-F1 + LEN-R1), $550 \mathrm{bp}$ (positions 94-665) (LEN-F1 + LEN-R2), $340 \mathrm{bp}$ (positions 
Eggerthella lenta gen. nov., comb. nov.

Table 3. Results of species-specific PCR

Results of PCR with various primers are shown as positive $(+)$ or negative $(-)$.

\begin{tabular}{|c|c|c|c|c|c|}
\hline \multirow[t]{2}{*}{ Taxon } & \multirow[t]{2}{*}{ Strain } & \multicolumn{4}{|c|}{ Primers } \\
\hline & & $\begin{array}{r}\text { LEN-F1+ } \\
\text { LEN-R1 }\end{array}$ & $\begin{array}{r}\text { LEN-F1 + } \\
\text { LEN-R2 }\end{array}$ & $\begin{array}{r}\text { LEN-F2 + } \\
\text { LEN-R1 }\end{array}$ & $\begin{array}{r}\text { LEN-F2 } \\
\text { LEN-R2 }\end{array}$ \\
\hline Eubacterium lentum & JCM 9979 & + & + & + & + \\
\hline Collinsella aerofaciens & JCM $10188^{\mathrm{T}}$ & - & - & - & - \\
\hline Coriobacterium glomerans & JCM $10262^{\mathrm{T}}$ & - & - & - & - \\
\hline Eubacterium limosum & $\mathrm{JCM} 6421^{\mathrm{T}}$ & - & - & - & - \\
\hline Eubacterium barkeri & $\mathrm{JCM} 1389^{\mathrm{T}}$ & - & - & - & - \\
\hline Atopobium minutum & $\mathrm{JCM} 1118^{\mathrm{T}}$ & - & - & - & - \\
\hline Eubacterium fossor & JCM $9981^{\mathrm{T}}$ & - & - & - & - \\
\hline Eubacterium combesii & $\mathrm{JCM} 9988^{\mathrm{T}}$ & - & - & - & - \\
\hline Eubacterium multiforme & $\mathrm{JCM} 6484^{\mathrm{T}}$ & - & - & - & - \\
\hline Eubacterium nitritogenes & $\mathrm{JCM} 6485^{\mathrm{T}}$ & - & - & - & - \\
\hline Eubacterium tenue & $\mathrm{JCM} 6486^{\mathrm{T}}$ & - & - & - & - \\
\hline Eubacterium moniliforme & JCM $9990^{\mathrm{T}}$ & - & - & - & - \\
\hline Eubacterium cylindroides & JCM $10261^{\mathrm{T}}$ & - & - & - & - \\
\hline Lactobacillus plantarum & JCM $1149^{\mathrm{T}}$ & - & - & - & - \\
\hline Bifidobacterium bifidum & $\mathrm{JCM} 1255^{\mathrm{T}}$ & - & - & - & - \\
\hline Propionibacterium propionicum & $\mathrm{JCM} 5830^{\mathrm{T}}$ & - & - & - & - \\
\hline Novel strain & A2-3 & + & + & + & + \\
\hline Novel strain & A2-184 & + & + & + & + \\
\hline Novel strain & A3-99 & + & + & + & + \\
\hline Novel strain & A3-104 & + & + & + & + \\
\hline Novel strain & A3-112 & + & + & + & + \\
\hline Novel strain & A3-125 & + & + & + & + \\
\hline Novel strain & A3-252 & + & + & + & + \\
\hline Novel strain & A5-166 & + & + & + & + \\
\hline Novel strain & A $5-189$ & + & + & + & + \\
\hline Novel strain & A5 -190 & + & + & + & + \\
\hline Novel strain & A9-162 & + & + & + & + \\
\hline Novel strain & RCA1-1 & + & + & + & + \\
\hline Novel strain & RCA1-16 & + & + & + & + \\
\hline Novel strain & RCA1-18 & + & + & + & + \\
\hline Novel strain & RCA2-10 & + & + & + & $t$ \\
\hline Novel strain & RCA2-37 & + & + & + & + \\
\hline Novel strain & RCA58-92 & + & + & + & + \\
\hline
\end{tabular}

139-497) (LEN-F2 + LEN-R1) and 507 bp (positions 139-665) (LEN-F2 + LEN-R2). The specificity of the primers was checked against published rRNA sequences. The results showed that LEN-F1, LEN-F2 and LEN-R1 did not match any published rRNA sequences; LEN-R2 has identity $(<91 \%)$ to three bacterial taxa (Afipia genospecies, Rhodoplanes elegans and Actinoplanes brasiliensis). Since PCR was done using a combination of two primers, this was not a problem. Firstly, we used Eubacterium lentum JCM $9979^{\mathrm{T}}$ DNA as a positive control and Collinsella aerofaciens JCM $10188^{\mathrm{T}}$ DNA as a negative control. The PCR results showed that all primers were positive for Eubacterium lentum and all were negative for Collinsella aerofaciens (Fig. 3). Thus, these primers are all specific for Eubacterium lentum. Secondly, we attempted PCR with other Eubacterium species and other genera. The results showed that Eubacterium lentum was positive, but all other species were negative (Table 3). Finally, we attempted PCR with Eubacterium lentum-like strains isolated from human faeces (Table 1). These strains were Gram-positive, non-spore-forming, anaerobic rods that did not produce acid from arabinose, xylose, rhamnose, ribose, glucose, mannose, fructose, sucrose, maltose, cellobiose, lactose, trehalose, melibiose, raffinose, melezitose, starch, glycogen, inulin, glycerol, mannitol, sorbitol, inositol, aesculin, salicin or amygdalin. The results of PCR showed that all strains examined were amplified (Table 3). This PCR method using Eubacterium lentum species-specific primers was very useful for identification. 


\section{DISCUSSION}

Eubacterium lentum is classified as a member of the genus Eubacterium because of its phenotypic characters. The genus Eubacterium has a broad definition and has over the years acted as a depository for a large number of phenotypically diverse species. In addition to this marked phenotypic heterogeneity, it is recognized that members of the genus Eubacterium are not phylogenetically homogeneous, with species dispersed among many genera, and some organisms are not related phylogenetically. The type species of the genus Eubacterium is Eubacterium limosum. It is evident from recent studies that Eubacterium limosum, Eubacterium barkeri and Eubacterium callanderi (Mountfort et al., 1988) can form the nucleus of a redefined genus Eubacterium. On the basis of the characteristics of this group, a preliminary working definition of Eubacterium sensu stricto may be as follows.

Gram-positive, rod-shaped organisms that are nonmotile and obligately anaerobic, may form endospores and are saccharolytic. The main products of glucose fermentation are butyrate, acetate, lactate and $\mathrm{H}_{2}$. Formate or $\mathrm{CO}_{2}$ may also be produced by some strains. The cell walls contain type B2 peptidoglycan. The $\mathrm{G}+\mathrm{C}$ content of the DNA is $45-47 \mathrm{~mol} \%$ (Willems \& Collins, 1996).

From previous studies, it is well known that Eubacterium lentum is unique within the genus Eubacterium in that it has methylated menaquinone (MMK-6) in addition to menaquinone (MK-6): other species that belong to the genus Eubacterium do not contain menaquinone but Eubacterium lentum pos-

Table 4. Characteristics that differentiate Eubacterium lentum and Eubacterium sensu stricto

Data were taken from Schleifer \& Kandler (1972) unless indicated by a (Nakazawa \& Hoshino, 1994) or b (Fresia \& Collins, 1987). Formation is scored as: + , positive; - , negative; or $(+)$, variable.

\begin{tabular}{|lcc|}
\hline Characteristic & $\begin{array}{c}\text { Eubacterium } \\
\text { lentum }\end{array}$ & $\begin{array}{c}\text { Eubacterium } \\
\text { sensu stricto }\end{array}$ \\
\hline Utilization of sugars & Asaccharolytic & Saccharolytic \\
Formation of: & - & \\
$\mathrm{H}_{2}$ & - & + \\
$\mathrm{CO}_{2}$ & - & $(+)$ \\
Butyrate & $(+)$ & + \\
Formate & $(+)$ & $(+)$ \\
Lactate & - & + \\
Acetate & $62^{\mathrm{a}}$ & $45-47$ \\
DNA G+C content & & $\mathrm{B} 2 \alpha$ \\
(mol \%) & A3 $3 \gamma$ & None $^{\mathrm{b}}$ \\
Cell-wall type & MK-6, MMK- $6^{\mathrm{b}}$ & \\
Menaquinone type & & \\
\hline
\end{tabular}

sesses significant amounts of MK-6 and MMK-6 (Fresia \& Collins, 1987). The cell walls contain type A3 peptidoglycan (Schleifer \& Kandler, 1972). Eubacterium lentum contains a branched-chain fatty acid as a major component; $66 \%$ of strains contain $12-$ methyl tetradecanoic acid (a-15:0) (Itoh et al., 1995). Phenotypic characteristics that differentiate Eubacterium lentum from Eubacterium sensu stricto are given in Table 4.

In order to clarify the phylogenetic position of Eubacterium lentum, the $16 \mathrm{~S}$ rRNA sequence was determined. A database search revealed that Eubacterium lentum belongs to the actinomycetes line. A new hierarchical classification structure for the taxa between the taxonomic levels of genus and class has been proposed for the actinomycete line of descent, as defined by analysis of a small-subunit (16S) rRNA and genes encoding this molecule (rDNA). A new class, Actinobacteria, including the orders Acidimicrobiales, Rubrobacterales, Coriobacteriales, Sphaerobacterales, Actinomycetales and Bifidobacteriales, has been discussed (Stackebrandt et al., 1997). Eubacterium lentum belongs to order Coriobacteriales, family Coriobacteriaceae, and this family contains the genera Coriobacterium and Atopobium in the new classification. A phylogenetic analysis was performed including all members of the family Coriobacteriaceae. Our analysis shows that Eubacterium lentum is near to Collinsella aerofaciens (Kageyama et al., 1999) and Coriobacterium glomerans (Haas \& König, 1988) by this method. The two phylogenetic trees have the same topology.

The $\mathrm{G}+\mathrm{C}$ content of Eubacterium lentum is $62 \mathrm{~mol} \%$ (Nakazawa \& Hoshino, 1994), which is different from that of the genus Eubacterium sensu stricto (45$47 \mathrm{~mol} \%$ ) and very similar to that of Collinsella aerofaciens and Coriobacterium glomerans (both 60$61 \mathrm{~mol} \%$ ). The $\mathrm{G}+\mathrm{C}$ content is similar but the phenotypic characters were not the same.

A PCR method using species-specific primers was established as an accurate and rapid method for identification of Eubacterium lentum. Two sets of Eubacterium lentum-specific primers were designed: LEN-F1, LEN-F2, LEN-R1 and LEN-R2. These primers were checked for similarity to other species by a homology search. The result showed that no pair of primers annealed to DNA of other species. The specificity of the primers was checked using the following organisms: Eubacterium lentum, Eubacterium limosum, Eubacterium barkeri, Eubacterium fossor, Eubacterium combesii, Eubacterium multiforme, Eubacterium nitritogenes, Eubacterium tenue, Eubacterium moniliforme, Eubacterium cylindroides, Collinsella aerofaciens, Coriobacterium glomerans, Atopobium minutum, Lactobacillus plantarum, Bifidobacterium bifidum and Propionibacterium propionicum (Coriobacteriaceae, Eubacterium and other anaerobic, Gram-positive, non-spore-forming rods). The results showed that each pair of primers was positive only 
for Eubacterium lentum; the primers are therefore useful for identification of Eubacterium lentum. Using this PCR system, Eubacterium lentum was differentiated from phylogenetically related Coriobacteriaceae species and phenotypically related Eubacterium species and anaerobic, Gram-positive, non-spore-forming rods. Finally, Eubacterium lentum-like strains that were isolated from human faeces were identified using this PCR method and 17 Eubacterium lentum-like strains were identified.

From the 16S rRNA gene sequence comparison, it was evident that the bacterium has a close phylogenetic relationship with Collinsella aerofaciens and Coriobacterium glomerans. This sequence divergence suggests that the bacteria are phylogenetically closely related, but nevertheless of different genera. In contrast to Collinsella aerofaciens and Coriobacterium glomerans, which contain type-A4 peptidoglycan, Eubacterium lentum contains type-A3 peptidoglycan. On the basis of the $16 \mathrm{~S}$ rRNA sequence and the unique type-A3 peptidoglycan, we propose that Eubacterium lentum should be classified as the type species of a new genus, with the name Eggerthella lenta gen. nov., comb. nov.

\section{Description of Eggerthella gen. nov.}

Eggerthella (Eg.ger.thel'la. L. dim. ending -ella; M.L. fem. n. Eggerthella named after A. H. Eggerth, a microbiologist who was the first person to isolate this strain).

Cells occur singly and in pairs and short chains. Grampositive. Obligately anaerobic. Spores and flagella are absent. The fermentation products of glucose are acetate, lactate and succinate. Hydrogen is not produced. Catalase activity is not detected. Gelatin is not liquefied, aesculin is not hydrolysed and nitrate is reduced. The cell wall contains A3 $\gamma$-type peptidoglycan. Major amounts of MK-6 and MMK-6 are present. The DNA $\mathrm{G}+\mathrm{C}$ content is $62 \mathrm{~mol} \%$. The type species is Eggerthella lenta. The genus Eggerthella is a member of the Coriobacteriaceae and exhibits a close phylogenetic association with the genera Coriobacterium and Collinsella.

\section{Description of Eggerthella lenta [Eubacterium lentum (Eggerth 1935) Prévot 1938] comb. nov.}

Eggerthella lenta (len'ta. L. fem. adj. lenta slow).

The cells are $0 \cdot 2-0 \cdot 4 \times 0 \cdot 2-2 \cdot 0 \mu \mathrm{m}$ and occur singly and in pairs and short chains. Colonies are $0.5-2.0 \mathrm{~mm}$, circular, entire to erose, raised to low-convex, translucent to semi-opaque, dull to shiny, smooth and sometimes with a mottled appearance when viewed by obliquely transmitted light on EG agar plates. Grampositive. Obligately anaerobic. Spores and flagella are absent. The fermentation products of glucose are acetate, lactate and succinate. Hydrogen is not produced. Catalase activity is not detected. Gelatin is not liquefied, aesculin is not hydrolysed and nitrate is reduced. The cells do not produce acid from arabinose, xylose, rhamnose, ribose, glucose, mannose, fructose, sucrose, maltose, cellobiose, lactose, trehalose, melibiose, raffinose, melezitose, starch, glycogen, inulin, glycerol, mannitol, sorbitol, inositol, aesculin, salicin or amygdalin. The cell wall contains A3 $\gamma$-type peptidoglycan. Major amounts of MK -6 and MMK-6 are present. Fatty acid composition consists of branched-chain fatty acids as major components : $66 \%$ of strains contain 12-methyl tetradecanoic acid (a$15: 0$ ). The DNA $\mathrm{G}+\mathrm{C}$ content is $62 \mathrm{~mol} \%$. The type strain of Eggerthella lenta is JCM $9979^{\mathrm{T}}$ (= DSM $2243^{\mathrm{T}}=$ ATCC $25559^{\mathrm{T}}=$ NCTC $11813^{\mathrm{T}}$ ).

\section{NOTE ADDED IN PROOF}

After this paper was accepted for publication, W. G. Wade and others described the transfer of Eubacterium lentum to Eggerthella lenta gen. nov., comb. nov. [Int $J$ Syst Bacteriol 49, 595-600 (1999)]. The description of Eggerthella lenta (Moore et al., 1971) Wade et al. 1999 has priority in nomenclature. However, our description of the new genus should be added to the description of Wade et al. (1999).

\section{ACKNOWLEDGEMENTS}

This work was supported by a grant from the Yakult Foundation for Bioscience Research.

\section{REFERENCES}

Benno, Y., Suzuki, K., Suzuki, K., Narisawa, K., Bruce, W. R. \& Mitsuoka, T. (1986). Comparison of the fecal microflora in rural Japanese and urban Canadians. Microbiol Immunol 30 , $521-532$.

Chandrasekaran, A., Robertson, L. W. \& Reuning, R. H. (1987). Reductive inactivation of digitoxin by Eubacterium lentum cultures. Appl Environ Microbiol 53, 901-904.

Eggerth, A. H. (1935). The Gram-positive non-spore-bearing anaerobic bacilli of human feces. J Bacteriol 30, 277-299.

Felsenstein, J. (1985). Confidence limits on phylogenies: an approach using the bootstrap. Evolution 39, 783-791.

Finegold, S. M. \& Sutter, V. L. (1978). Fecal flora in different populations with special reference to diet. Am J Clin Nutr 27, 1456-1469

Fresia, F. \& Collins, M. D. (1987). Vitamin K composition of anaerobic gut bacteria. FEMS Microbiol Lett 41, 175-180.

Haas, H. \& König, H. (1988). Coriobacterium glomerans gen. nov., sp. nov. from the intestinal tract of the red soldier bug. Int $J$ Syst Bacteriol 38, 382-384.

Hatta, M. (1995). Antitumor mechanisms of Eubacterium lentum and its components. Asian Pac J Allergy Immunol 13, 129-137.

Itoh, U., Sato, M., Tsuchiya, H. \& Namikawa, I. (1995). Cellular fatty acids and aldehydes of oral Eubacterium. FEMS Microbiol Lett 126, 69-74

Kageyama, A., Benno, Y. \& Nakase, T. (1999). Phylogenetic and 
phenotypic evidence for the transfer of Eubacterium aerofaciens to the genus Collinsella as Collinsella aerofaciens gen. nov., comb. nov. Int $J$ Syst Bacteriol 49, 557-565.

Kimura, M. \& Ohta, T. (1972). On the stochastic model for estimation of mutation distance between homologous proteins. $J$ Mol Evol 2, 87-90.

Moore, W. E. C. \& Holdeman, L. V. (1974). Human fecal flora: the normal flora of 20 Japanese-Hawaiians. Appl Microbiol 27, 961-979.

Moore, W. E. C., Cato, E. P. \& Holdeman, L. V. (1971). Eubacterium lentum (Eggerth) Prévot 1938: emendation of description and designation of the neotype strain. Int J Syst Bacteriol 21, 307-310.

Morinaga, S., Sakamoto, K. \& Konishi, K. (1988). Antitumor activity and properties of Eubacterium lentum. Jpn J Cancer Res 79, 117-124.

Mountfort, D. O., Grant, W. G., Clarke, R. \& Asher, R. A. (1988). Eubacterium callanderi sp. nov. that demethoxylates $O$ methoxylated aromatic acids to volatile fatty acids. Int $J$ Syst Bacteriol 38, 254-258.

Nakazawa, F. \& Hoshino, E. (1994). Genetic relationships among Eubacterium species. Int J Syst Bacteriol 44, 787-790.

Prévot, A. R. (1938). Études de systématique bactérienne. III. Invalidité du genre Bacteroides Castellani et Chalmers. Démembrement et reclassification. Ann Inst Pasteur Paris 60 , 295.
Saitou, N. \& Nei, M. (1987). The neighbor-joining method: a new method for reconstructing phylogenetic trees. Mol Biol Evol 4, 406-425.

Schleifer, K. H. \& Kandler, O. (1972). Peptidoglycan types of bacterial cell walls and their taxonomic implications. Bacteriol Rev 36, 407-477.

Stackebrandt, E., Rainey, F. A. \& Ward-Rainey, N. L. (1997). Proposal for a new hierarchic classification system, Actinobacteria classis nov. Int J Syst Bacteriol 47, 479-491.

Thompson, J. D., Higgins, D. G. \& Gibson, T. J. (1994). CLUSTAL $\mathrm{w}$ : improving the sensitivity of progressive multiple sequence alignment through sequence weighting, position-specific gap penalties and weight matrix choice. Nucleic Acids Res 22, 4673-4680.

Wade, W. G., Downes, J., Dymock, D., Hiom, S. J., Weightman, A. J., Dewhirst, F. E., Paster, B. J., Tzellas, N. \& Coleman, B. (1999). The family Coriobacteriaceae: reclassification of Eubacterium exiguum (Poco et al. 1996) and Peptostreptococcus heliotrinreducens (Lanigan 1976) as Slackia exigua gen. nov., comb. nov. and Slackia heliotrinreducens gen. nov., comb. nov., and Eubacterium lentum (Prevot 1938) as Eggerthella lenta gen. nov., comb. nov. Int J Syst Bacteriol 49, 595-600.

Willems, A. \& Collins, M. D. (1996). Phylogenetic relationships of the genera Acetobacterium and Eubacterium sensu stricto and reclassification of Eubacterium alactolyticum as Pseudoramibacter alactolyticus gen. nov., comb. nov. Int J Syst Bacteriol 46, 1083-1087. 